$\mathbb{P}$ periodica polytechnica

Chemical Engineering

57/1-2 (2013) 71 77

doi: $10.3311 /$ PPch.2173

http://periodicapolytechnica.org/ch

Creative Commons Attribution (i)

RESEARCH ARTICLE

\section{Nucleate pool boiling heat transfer of binary nano mixtures under atmospheric pressure around a smooth horizontal cylinder}

\author{
M.M. Sarafraz / S.M. Peyghambarzadeh / S.A. Alavi Fazel / N. Vaeli \\ Received 2012-10-12, accepted 2013-04-07
}

\begin{abstract}
Influence of $\mathrm{Al}_{2} \mathrm{O}_{3}$ nanoparticles on nucleate pool boiling heat transfer of diluted binary water-glycerol mixtures has been experimentally measured up to heat flux $91 \mathrm{~kW} / \mathrm{m}^{2}$ at diluted volume fractions of $1 \%$ to $5 \%$ of glycerol into pure water at volumetric concentrations $0.5 \%, 1 \%$ and $1.5 \%$ of $\mathrm{Al}_{2} \mathrm{O}_{3}$ nanoparticles. Obtained results indicate that presence of nanoparticles into the mixtures result in increasing the pool boiling heat transfer coefficient values and also result in decreasing the wall superheat temperature of surface. Increased values of heat transfer are increased with increasing the volume fractions of $\mathrm{Al}_{2} \mathrm{O}_{3}$ too. Generally, it is concurred that $\mathrm{Al}_{2} \mathrm{O}_{3}$ nanoparticles typically enhance the pool boiling heat transfer coefficient of binary water-glycerol mixture in comparison with absence of nanoparticles circumstances, up to $25 \%$ at $1.5 \% \mathrm{Al}_{2} \mathrm{O}_{3}$. Additionally, new simple semi - mathematical model has been proposed for a rough estimating of enhanced values with uncertainty about $8 \%$.
\end{abstract}

\section{Keywords}

heat transfer $\cdot$ nucleate pool boiling $\cdot \mathrm{Al}_{2} \mathrm{O}_{3} \cdot$ water $\cdot$ glycerol . binary mixture $\cdot$ nanofluid

\section{Acknowledgement}

Authors of this research tend to appreciate "Tarbiat Modarres" research center for their disposed facilities and financial supports. Also they tend to thank Islamic Azad University of Iran (IAU) branch of mahshahr for their financial supports.

\section{M.M. Sarafraz}

Department of Chemical Engineering, Mahshahr branch, Islamic Azad University, Mahshahr, Iran

e-mail: mohamadmohsensarafraz@gmail.com

\section{S.M. Peyghambarzadeh}

\section{S.A. Alavi Faze}

Department of Chemical Engineering, Mahshahr branch, Islamic Azad University, Mahshahr, Iran

\section{N. Vaeli}

Department of Chemical Engineering, Shahrreza branch, Islamic Azad University, Shahrreza, Iran

\section{Introduction}

Nowadays, boiling heat transfer is widely used in many industrial processes including distillation, power generation cycle, and refrigeration. Design, operation and optimization of such units require an accurate value of boiling heat transfer coefficient. Also increasing the values of heat transfer coefficients could reduce the costs of design, operating and maintaining and helps engineers to design the optimized heat transfer industrial tools. Most of researchers have been investigating on usage and applications of nanofluids on improving the heat transfer coefficient which has not been generally usable in industrial yet. In recent years, the rapid development of engineering technologies has contributed significantly to the boiling heat transfer enhancement. Until now, some of the earlier proposed methods are increase of the heating surface area (fins), the application of an electrical field and the addition of solid particles that called additive to the tested solutions [1].

Nanofluid technology was created by Choi in the field of heat transfer [2]. Nanofluids are liquid suspensions containing nanoparticles $(<100 \mathrm{~nm})$ with thermal conductivities higher than the base liquids [3]. Some text scripts on nanofluids under boiling conditions and boiling of solutions have recently represented in the following literature.

Das et al. [4] studied nucleate pool boiling heat transfer of $\mathrm{Al}_{2} \mathrm{O}_{3}$-water nanofluids on the surface of a horizontal cylindrical cartridge. The presence of nanoparticles affected negatively the boiling performance and the negative impact became more important when the nanoparticle concentration was increased. Similar results were found in the later study by Das et al. [5] using smaller cartridges. These authors believed that the lower pool boiling performance was related to changes of the surface characteristics of the heater.

You et al. [6] studied pool boiling heat transfer of silica- water and alumina-water nanofluids at sub-atmospheric pressure. Results showed that the presence of nanoparticles increased the values of the critical heat flux (CHF). Witharana [7] studied the effect of gold nanoparticles on boiling heat transfer of water under atmospheric pressure and found a reasonable increase in nucleate boiling heat transfer. 
Vassllo et al. [8] investigated the pool boiling heat transfer behavior of silica-water nanofluids on a horizontal $\mathrm{Ni}-\mathrm{Cr}$ wire under atmospheric pressure. Although their experiments illustrated a $200 \%$ CHF increase, no significant heat transfer coefficient enhancement was observed.

Tu et al. [9] obtained a significant increase in both boiling heat transfer coefficient and critical heat flux with $\mathrm{Al}_{2} \mathrm{O}_{3}$-water nanofluids. Bang and Chang [10] investigated on experimental research to the pool boiling of $\mathrm{Al}_{2} \mathrm{O}_{3}$-water nanofluids on a plain plate. The concentration of used nanoparticles was $0.5 \%, 1 \%$, $2 \%$, and $4 \%$ by volume. It was found that the boiling curves were shifted right - towards higher wall superheats. The decreasing became worse as nanoparticle concentration increased and was related to the change of the heating surface properties by the deposition of dispersed nanoparticles on the heating surface.

Wen and Ding [11] studied pool boiling of $\mathrm{Al}_{2} \mathrm{O}_{3}$-water nanofluids on a stainless steel disc with $150 \mathrm{~mm}$ in diameter. Contrary to the Bang and Chang's research, heat transfer enhancement has been observed. Possible explanation of this controversy is lower concentration of used nanoparticles $(0.32 \%)$ and geometry and circumstances of heating surface.

Shi et al. [12] investigated on the experiments with boiling of $\mathrm{Al}_{2} \mathrm{O}_{3}$-water nanofluid and $\mathrm{Fe}$-water nanofluid on horizontal, copper plate with $60 \mathrm{~mm}$ in diameter. The concentration of nanoparticles was $0.1 \%, 1 \%$, and $2 \%$ by volume. Generally, the augmentation and deterioration of heat transfer was recorded for water-Fe and water- $\mathrm{Al}_{2} \mathrm{O}_{3}$ nanofluids, respectively.

Nguyen et al. [13] investigated nucleate pool boiling of water$\mathrm{Al}_{2} \mathrm{O}_{3}$ nanofluid on chrome-plated, very smooth face of copper block of a $100 \mathrm{~mm}$ diameter. The concentration of nanoparticles was $0.5 \%, 1 \%$, and $2 \%$ by volume. In general, it was observed that for a given wall superheat, the heat flux considerably decreased with the increase of the particle concentration. Superheat, the heat flux tended to become nearly constant.

Coursey and $\mathrm{Kim}$ [14] proved that even if the $\mathrm{Al}_{2} \mathrm{O}_{3}$ nanoparticle concentration was increased by over two orders of magnitude, no enhancement or degradation of heat transfer was recorded during boiling of ethanol-based nanofluids on glass or gold surface. It was attributed to the highly wetting nature of ethanol. For ethanol- $\mathrm{Al}_{2} \mathrm{O}_{3}$ nanofluids and copper surfaces, the nucleate boiling was improved with increasing nanoparticle concentration.

Liu and Liao [15] tested the mixture of base fluid (water and alcohol) and ( $\mathrm{CuO}$ and $\left.\mathrm{SiO}_{2}\right)$ nanoparticles and the (SDBS), surfactant. Nanoparticles suspensions consisted of the base liquid and nanoparticles during pool boiling around the surface of copper bar having $20 \mathrm{~mm}$ diameter. However details of surface were unknown. The boiling characteristics of the nanofluids and nanoparticles- suspensions are poorer comparing with the base fluids.

Trisaksri and Wongwises [16] tested $\mathrm{R} 141 \mathrm{~b}-\mathrm{TiO}_{2}$ nanofluids while boiling on horizontal copper cylinder $28.5 \mathrm{~mm}$ diameters.
They discovered that adding a small amount of nanoparticles did not influence on boiling heat transfer rate, but addition of $\mathrm{TiO}_{2}$ nanoparticles at $0.03 \%$ and $0.05 \%$ by volume deteriorated the boiling heat transfer [22]. Moreover, the boiling heat transfer coefficient decreased with increasing particle volume concentrations, especially at higher heat flux.

Kathiravan et al. [17] investigated boiling of water- $\mathrm{Cu}$ and water-Cu-SDS (9 wt. \%) nanofluids on a $300 \mathrm{~mm}$ square stainless steel plate. They found out that copper nanoparticles caused a decreasing in boiling heat transfer coefficient for water as base liquid. The heat transfer coefficient decreased with increase of the concentration of nanoparticles $(0.25 \%, 0.5 \%$, and $1 \%$ by weight) for both water- $\mathrm{Cu}$ and water-Cu-SDS nanofluids.

Suriya-wong and Wongwises [18] studied boiling of water$\mathrm{TiO}_{2}$ nanofluids on horizontal circular plates made from copper and aluminum with different roughness $(0.2$ and $4 \mu \mathrm{m})$. The concentration of nanoparticles was very low: $0.00005 \%, 0.0001 \%$, $0.0005 \%, 0.005 \%$, and $0.01 \%$ by volume. For copper plate with nanofluids concentrations more than $0.0001 \%$, the heat transfer coefficient was found to be less than that of the base fluid at both levels of surface roughness. On the other hand, for aluminum surfaces the heat transfer coefficient was found to be less than that of base fluid at every level of nanofluids concentration and surface roughness [22].

Ahmed and Hamed [19] performed experiments with boiling of water- $\mathrm{Al}_{2} \mathrm{O}_{3}$ on a face of copper block of $25.4 \mathrm{~mm}$ diameter. Nanofluids at $0.01 \%, 0.1 \%$, and $0.5 \%$ by volume concentrations were prepared at a neutral $\mathrm{PH}$ of 6.5 and an acidic $\mathrm{PH}$ of 5. Ultrasonic vibration and electrostatic stabilization were used to prepare nanofluids. It was found that concentration increase either reduced or had no effect on heat transfer coefficient. Enhancement of heat transfer coefficient was achieved only at low nanofluid concentration $(0.01 \%)$ and the nanofluid at a $\mathrm{PH}$ of 6.5 .

Recently, Kwark et al. [20] have pointed out the transient characteristics of water- $\mathrm{Al}_{2} \mathrm{O}_{3}$ nanofluid boiling on horizontal copper plate. The heater is subjected to the nanofluid boiling process, a layer of nanoparticle coating generated on its surface. In the work of Das et al. experiments were carried out to evaluate pool boiling with nanofluids of 1,2 and $4 \%$ of $\mathrm{Al}_{2} \mathrm{O}_{3}$ nanoparticle concentrations in water. The effects of particle concentration, heater diameter, and surface roughness of the heater on the boiling characteristic of nanofluids were studied. The presented results were somewhat contrary to expectations; nanofluids were expected to enhance the heat transfer characteristic during pool boiling. However, the boiling curves of nanofluids indicated that the boiling performance of the water deteriorated with the addition of nanoparticles, since the boiling curves were shifted to the right. The shift of the curves was proportional to the particle concentration and dependent on the tube roughness, and the deterioration of the heat transfer performance was stronger with smoother surfaces. Deeply investigating, in some experiments regardless to the surface rough- 
ness, effect of adding of nanofluids into base fluid have been directly investigated. Mainly with smoother surface, deterioration of heat transfer has been reported. On the other hand, representing more details about quality of heated surface, such as purity and homogenization of surface, has been neglected in some works that strongly influence on surface temperature and heat transfer coefficient. Also Faced with these contradictions, it is obvious that a better understanding of the impact of nanoparticles on pool boiling heat transfer is required [1, 22].

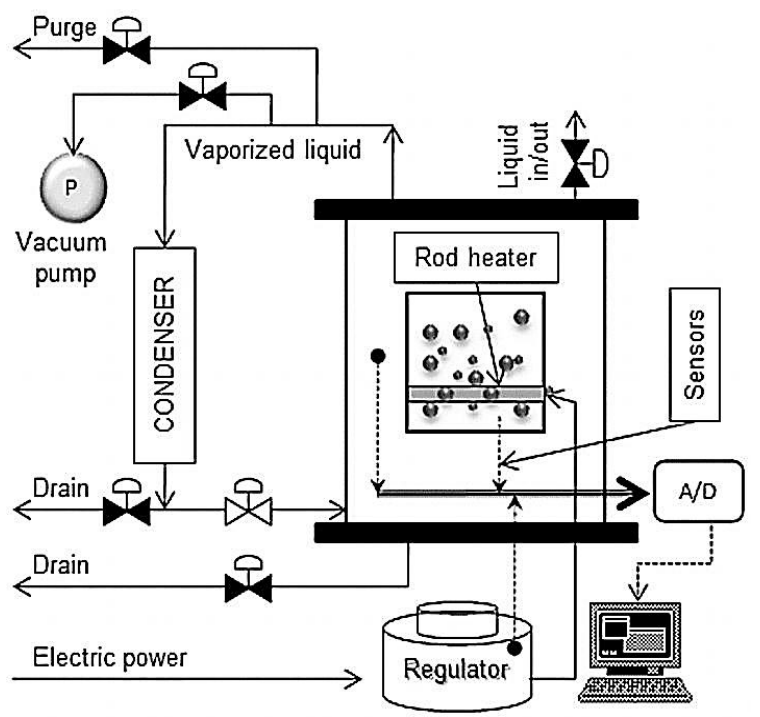

Fig. 1. A scheme of experimental apparatus of pool boiling

\section{Experimental}

\subsection{Experimental Setup}

Fig. 11 shows the experimental setup which has been used in this research. The horizontal smooth cylinder (which was polished several times) with average roughness about $0.0345 \mu \mathrm{m}$ has been considered for apparatus which has $200 \mathrm{~mm}$ length and $21 \mathrm{~mm}$ diameter. The roughness value was experimentally measured using profile meter (Phase II, SRG-1000). The main test vessel is a stainless steel with $200 \mathrm{~mm} \times 100 \mathrm{~mm} \times 100 \mathrm{~mm}$ and a DC $1000 \mathrm{~W}$ cartridge heater has been employed to supply the needed heat fluxes and also a $1500 \mathrm{~W}$ DC power supplier has been used during all the experiment steps as a source of power. $14 \mathrm{~K}$-type thermocouples have been installed at circumference of heating section near the surface to measure the surface temperature accurately, likewise for minimizing the contact thermal resistance a high quality silicon paste was injected into the thermocouple wells. In addition to, three PT-type thermocouples have been installed for estimating the saturation temperature of mixtures. Fig. 1 shows the cross section of stainless steel horizontal heating section. Also, front view in Fig. 2. schematically represents more details of heating section.

\subsection{Preparing nanofluid solution}

To prepare the nanofluid, it is necessary to disperse the dry nanoparticles uniformly into the whole base fluid. Glycerol - water at various volume fractions of glycerol were selected as a base fluid. A magnetic stirrer has been used to disperse the particles (which were mostly 49-50nm in size (diameter) and were nearly spherical) for about $8 \mathrm{hr}$. To count the particle, nanoparticle tracking analysis (NTA method) was employed to ensure that there is no significant, agglomerated particle inside the vessel. Accordingly, to count the particles and particle sizes, sixteen samples were provided from sixteen different place of tested vessel and was analyzed using a micro scale capturing device counting the number of particles clearly. After all, arithmetic average of obtained results of all samples is used as a accurate result. Also for the best stabilization, an ultrasonic gun has been employed one hour before running the experiments to prevent of agglomeration constitution and improving the quality of nanofluid stability. Nanoparticles size distribution curve is given in Fig. 3 .

Additionally, to investigate the circumstance of agglomeration phenomenon in tested nanofluid, high resolution TEM images were provided to ensure that no agglomeration has been occurred. Figure 4 clearly shows that $\mathrm{Al}_{2} \mathrm{O}_{3}$ nanoparticles are well-dispersed into the base fluid. It is noticeable that TEM images were taken more than three times.

\subsection{Horizontal cylinder}

To eliminate the effect of roughness of surface on pool boiling heat transfer mechanisms, the stainless steel cylinder has been polished several times. Profile meter results show that roughness of surface is reasonable and is adaptable with standard roughness reference for smooth surfaces that is closely equal to 0.03 $0.04 \mu \mathrm{m}$. Fig. 5 shows the results of profile meter scanned image sample [22].

\subsection{Experimental procedure}

To calculate the real surface temperature by correcting the minor temperature drop due to the small distance between surface and thermocouple location, the Fourier's conduction equation
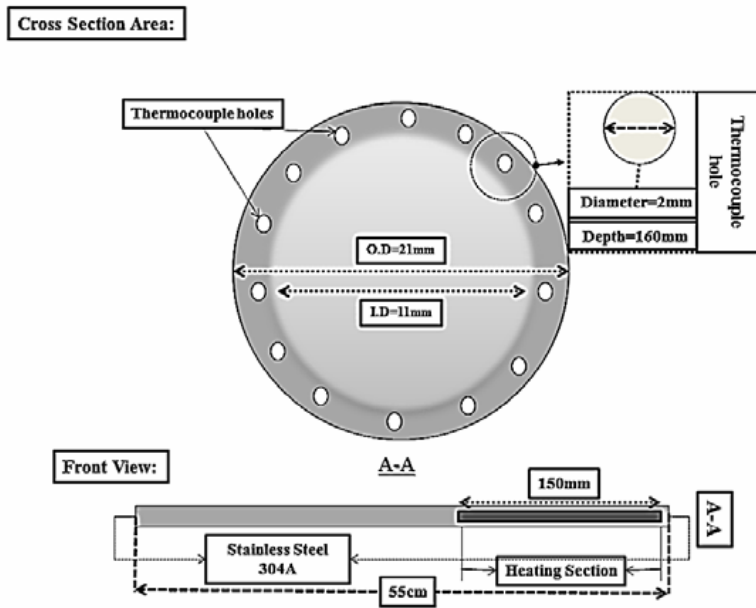

Fig. 2. Schematic of heating section 


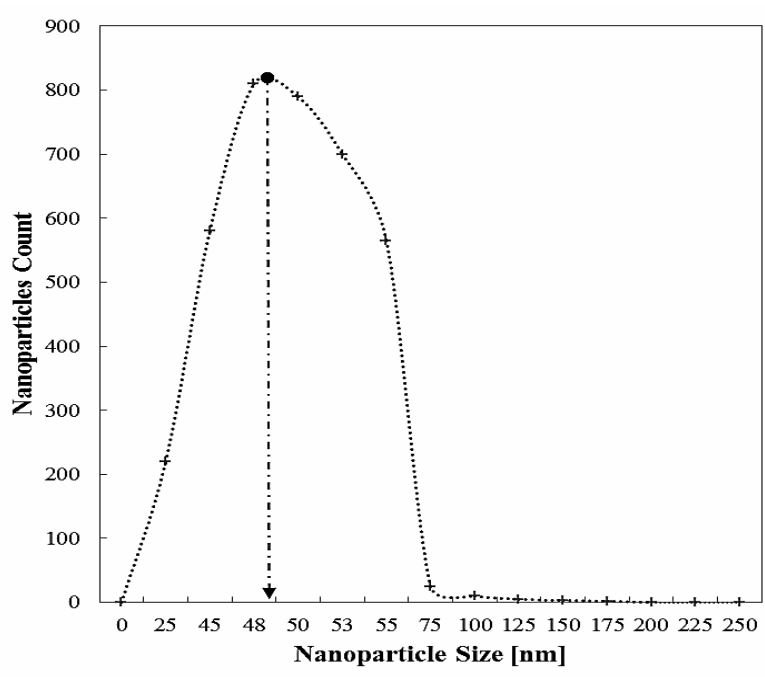

Fig. 3. Nanoparticle size distribution

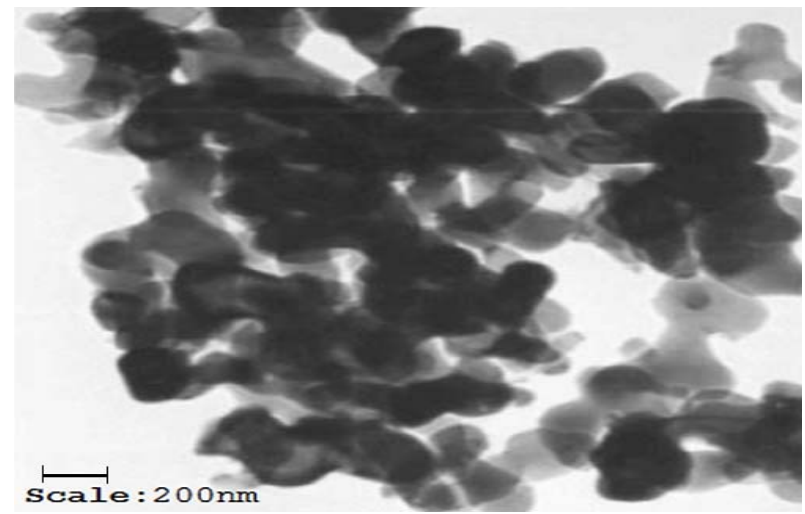

Fig. 4. High resolution TEM image of $\mathrm{Al}_{2} \mathrm{O}_{3}$ dispersed nanoparticle at scale $200 \mathrm{~nm}$

for cylinder shape is used as follow:

$$
T_{s}-T_{t h m}=V I \frac{\ln \left(\frac{r_{o}}{r_{i}}\right)}{2 \pi K L}
$$

where $T_{s}$ is real surface temperature, $T_{t h m}$ is arithmetic average of four installed thermocouples using Eq. (1), $\mathrm{V}$ is heater voltage and $\mathrm{I}$ is passing electric current of heater, $r_{o}$ and $r_{i}$ are outer and inner diameter of tube respectively. $L$ is effective length and $K$ is thermal conductivity of considered tube. The boiling heat transfer coefficient $(\alpha)$ is calculated by following equation. This equation is obtained from Newton's cooling law.

$$
\alpha=\frac{\frac{q}{A}}{\left(T_{s}-T_{b}\right)_{\text {ave }}}
$$

$q / A$ is called heat flux and is calculable multiplying the passing current and related voltage. $T_{s}$, as mentioned is obtained from arithmetic average of fourteen thermocouples. $T_{b}$ is also obtained from arithmetic average of three PT-1000 thermocouples that installed in top, bottom and middle of the vessel. For each experiment, to measure the uncertainty of experiment, mathematical least square method has been employed. According to heat flux estimating correlation:

$$
q "=\frac{V \cdot L}{2 \pi R_{o} L}=\frac{W}{2 \pi R_{o} L}
$$

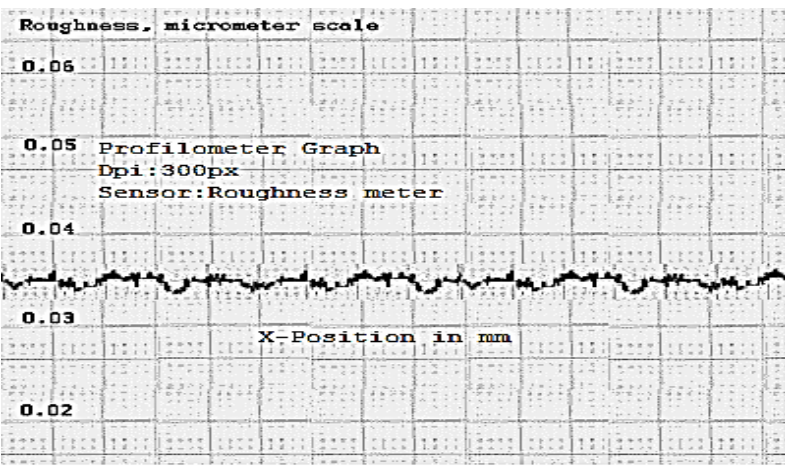

Fig. 5. Roughness of heating section surface provided by profile meter

Experimental uncertainty is obtained by following equation:

$$
\Delta q "=\sqrt{\left(\frac{\partial q "}{\partial w} \Delta w\right)^{2}+\left(\left(\frac{\partial q "}{\partial r} \Delta r\right)\right)^{2}+\left(\frac{\partial q "}{\partial L} \Delta L\right)^{2}}
$$

Values for $\Delta w, \Delta r, \Delta L$ are $8.5,0.3$ and 0.03 respectively.

Accordingly, pool boiling heat transfer coefficient uncertainty, according to the $\Delta q^{\prime \prime}$ values is obtained by Eq. (4) as follows:

$$
\Delta \alpha=\sqrt{\left(\frac{\partial \alpha}{\partial q^{\prime}} \Delta q^{\prime \prime}\right)^{2}+\left(\frac{\partial \alpha}{\partial T} \Delta T\right)^{2}}
$$

In this research, $\Delta T$ equals to $\pm 0.3 \mathrm{~K}$ according to accuracy of each thermocouple and $\Delta q^{\prime \prime}$ equals to $1.25 \%$ according to Eq. (4) and subsequently, uncertainty of estimating of heat transfer coefficient equals to $\pm 4.8 \%$. To carry the experiments out, initially, the entire system including the rod heater and the inside of the tank were cleaned and the test solution was introduced. The vacuum pump is then turned on and the pressure of the system is kept low approximately to $10 \mathrm{kPa}$ for five hour to allow all the dissolved gases especially the dissolved air has been stripped from the test solution. Following this, the tank band heater was switch on and the temperature of the system allowed rising to the saturation temperature. This procedure presents a homogeneous condition right through. Then the electric power was slowly supplied to the rod heater and increased gradually to a constant predetermined value. Data acquisition systems were simultaneously switched on to record the required parameters including the rod heater temperature, bulk temperature, heat flux. All experimental runs were carried out with decreasing heat flux to eliminate the hysteresis effect. Some runs were repeated twice and even more than three times to ensure the reproducibility of the experiments.

\section{Results and discussion}

In order to compare the heat transfer performance of mixture, initially, it is a need to run an experiment without adding nanoparticles. Later, obtained results, could be a comparable reference to show the effect of nanoparticles on values of nucleate pool boiling heat transfer coefficients. Fig. 6 typically represents the experimental data values for pool boiling heat transfer coefficients at various heat fluxes in comparison with pure water heat transfer coefficient. 


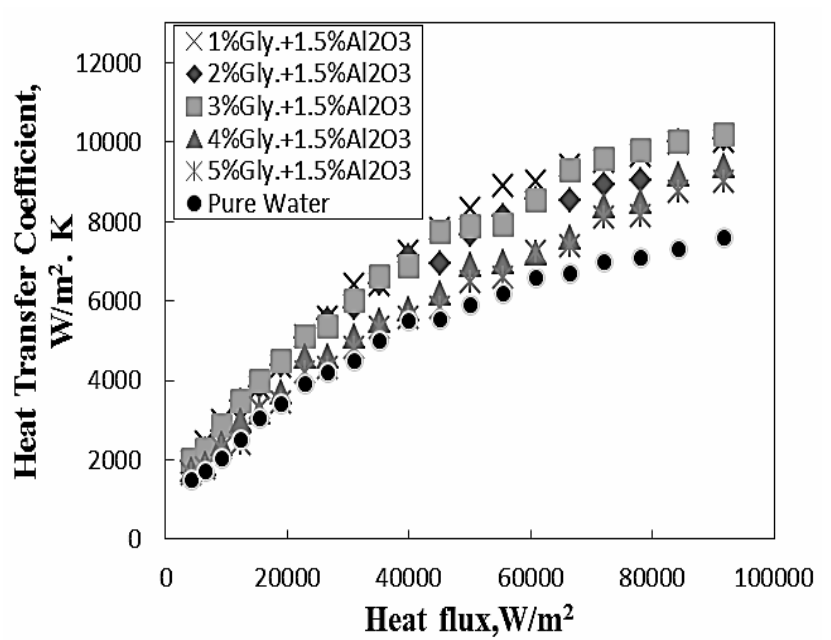

Fig. 6. Comparison between values of experimental values of heat transfer coefficient, alpha at various glycerol volume fraction

As seen in Fig 6, heat transfer coefficient is decreased with increasing the concentration of heavier component(s), glycerol. The major reason of this phenomenon refers to the difference of concentration of heavier component and light component in vapor/liquid interface. In boiling process, particularly in binary and multi mixtures, interface of vapor and liquid is depleted with lighter component(s) and is enriched by heavier component(s) due to the difference between their pressure vapors. Furthermore heavier components need more heat to evaporate and leave the interface out and in this special circumstance, more heat is needed and accordingly, with increasing in temperature of surface, heat transfer coefficient is reduced in comparison with the pure liquids. Although in boiling process of pure liquids, vapor and liquid phase and also vapor/liquid interface are the same and there is no mass transfer and any resistances besides the heat transfer process. However in mixtures more over than heat transfer mechanism, mass transfer between captured vapor of bubbles and bulk of solution and interface of liquid/vapor and vapor phase also exists. Hence, heat transfer coefficients of mixtures are lower than pure states. Also, for pure fluids the heat transfer increases with increase in viscosity but in the present case two competing phenomena are taking place, increase of heat transfer due to viscosity, decrease of heat transfer due to decrease of nucleation site density by plugging off (micro) surface cavities by nano-particles. The results indicate that the latter effect is dominant over the former, because the increase in viscosity is very marginal. Fig. 7]Shows the influence of presence of nanoparticle at different volume concentration of $\mathrm{Al}_{2} \mathrm{O}_{3}$ that leads to increase the pool boiling heat transfer coefficient. Also for accurate representing the enhanced values and related comparisons, Tables 1 to 5 have been prepared as follows:

As presented in Table 1 and following tables, presences of nanoparticles moreover than enhancing the thermal conductivity, enhance the wettability of surface that results in enhancing the heat transfer coefficient. Following tables can truly represent this fact.
During all of the experiments, it is obvious that enhancement values are strictly, taken as a direct function of nanoparticle concentrations. In this work, volumetric concentrations of $0.5,1$ and 1.5 percentage of $\mathrm{Al}_{2} \mathrm{O}_{3}$ have been investigated. Results show that maximum increase was observed at $1.5 \%$ volumetric of $\mathrm{Al}_{2} \mathrm{O}_{3}$ and was about $25 \%$ of based fluid heat transfer coefficient values. Also, for better understanding of foregoing tables, enhancing of heat transfer coefficient values have been schematically shown through the following figures.

As shown in Figure 7, with increasing the volumetric concentration of nanoparticles, heat transfer coefficients is strongly increased. Although this phenomenon is seen at other concentrations of $\mathrm{Al}_{2} \mathrm{O}_{3}$ nanoparticles and glycerol and increased values depend on the concentration values of nanoparticles. To ensure about direct influence of concentration of nanoparticles on heat transfer coefficient, several experiments have been carried out at various concentrations of glycerol and nanoparticles. Respect to the obtained results, presence of nanoparticles, however in low volumetric concentrations, enhance the values of heat transfer coefficients. For better comparison, all of the experimental data of base solution have been represented beside the measured heat transfer coefficient of nanomixture. In this circumstance, enhancing is clearly understandable. Fig. 8 typically show the increase of heat transfer coefficient due to nanoparticle presence, clearly:

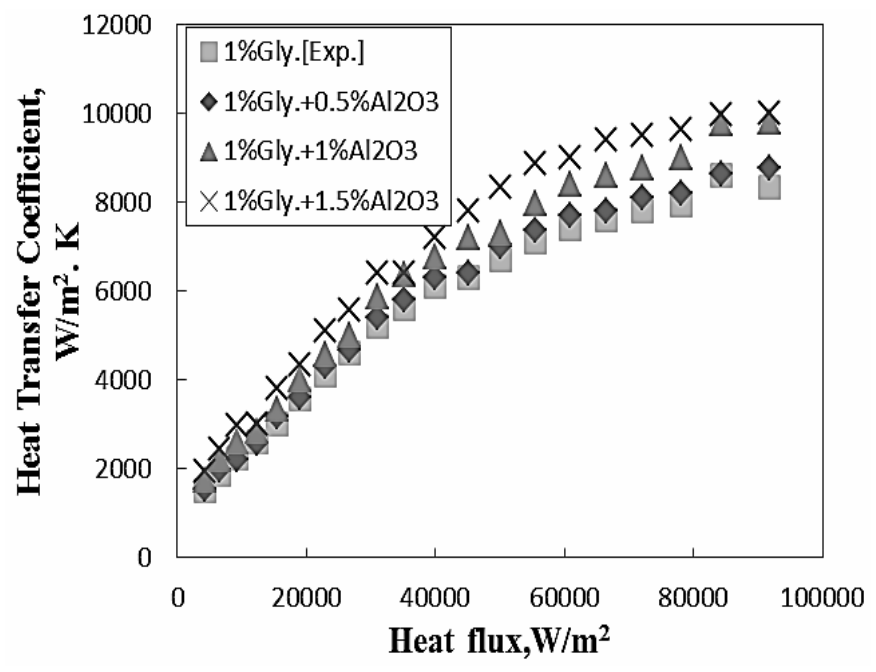

Fig. 7. Effect of adding nanofluid into mixture in comparison with experimental data of base solution fluid ( $1 \%$ volumetric Glycerol)

At $1.5 \%$ of $\mathrm{Al}_{2} \mathrm{O}_{3}$ nanoparticle concentration, values of pool boiling heat transfer coefficient become higher than pure water. Although at initial steps of experiment runs, all experimental values of base solution without any nanoparticle, were less than pure water (see Fig. 6 .

\section{Conclusion}

Influence of adding nanoparticles into a base solution fluid (water-glycerol) on pool boiling heat transfer coefficient at various volumetric concentrations of $\mathrm{Al}_{2} \mathrm{O}_{3}$ and different concen- 
Tab. 1. Enhancement values of heat transfer coefficient for $1 \%$ volumetric Water-Glycerol for $0.5 \%$, $1 \%$ and $1.5 \%$ of $\mathrm{Al}_{2} \mathrm{O}_{3}$ nanoparticle

\begin{tabular}{|c|c|c|c|c|}
\hline $\begin{array}{l}q / A \\
{\left[k W / m^{2}\right]}\end{array}$ & $\begin{array}{l}\alpha \text { (base fluid) } \\
\text { Water-Glycerol } \\
{\left[\mathbf{W} / \mathbf{m}^{2} . \mathbf{K}\right]}\end{array}$ & $\begin{array}{l}\alpha \text { Enhanced } \\
0.5 \% \mathrm{Al}_{2} \mathrm{O}_{3} \\
{\left[\mathrm{~W} / \mathrm{m}^{2} . \mathbf{K}\right]}\end{array}$ & $\begin{array}{l}\alpha \text { Enhanced } \\
1 \% \mathrm{Al}_{2} \mathrm{O}_{3} \\
{\left[\mathrm{~W} / \mathrm{m}^{2} . \mathrm{K}\right]}\end{array}$ & $\begin{array}{l}\alpha \text { Enhanced } \\
1.5 \% \mathrm{Al}_{2} \mathrm{O}_{3} \\
{\left[\mathrm{~W} / \mathrm{m}^{2} . \mathrm{K}\right]}\end{array}$ \\
\hline 10 & 2225 & 2242 & 2635 & 2990 \\
\hline 20 & 3224 & 3597 & 4054 & 4645 \\
\hline 40 & 6100 & 6300 & 6789 & 7730 \\
\hline 60 & 7408 & 7721 & 8431 & 9481 \\
\hline 70 & 7809 & 8140 & 8789 & 9905 \\
\hline 90 & 8339 & 9027 & 9802 & 10938 \\
\hline
\end{tabular}

Tab. 2. Enhancement values of heat transfer coefficient for $2 \%$ volumetric Water-Glycerol for $0.5 \%$, $1 \%$ and $1.5 \%$ of $\mathrm{Al}_{2} \mathrm{O}_{3}$ nanoparticle

\begin{tabular}{lllll}
\hline $\mathbf{q} / \mathbf{A}$ & $\alpha$ (base fluid) & $\alpha$ Enhanced & $\alpha$ Enhanced & $\alpha$ Enhanced \\
{$\left[\mathbf{k W} / \mathbf{m}^{2}\right]$} & $\begin{array}{l}\text { Water-Glycerol } \\
{\left[\mathbf{W} / \mathbf{m}^{2} \cdot \mathbf{K}\right]}\end{array}$ & $\begin{array}{l}\mathbf{0 . 5 \%} \mathbf{A l}_{2} \mathbf{O}_{3} \\
{\left[\mathbf{W} / \mathbf{m}^{2} \cdot \mathbf{K}\right]}\end{array}$ & $\begin{array}{l}\mathbf{1} \% \mathbf{A l}_{2} \mathbf{O}_{3} \\
{\left[\mathbf{W} / \mathbf{m}^{2} \cdot \mathbf{K}\right]}\end{array}$ & $\begin{array}{l}\mathbf{1 . 5} \% \mathbf{A l}_{2} \mathbf{O}_{3} \\
{\left[\mathbf{W} / \mathbf{m}^{2} \cdot \mathbf{K}\right]}\end{array}$ \\
\hline $\mathbf{1 0}$ & 2200 & 2288 & 2508 & 2728 \\
$\mathbf{2 0}$ & 3550 & 3692 & 4047 & 4402 \\
$\mathbf{4 0}$ & 5757 & 5988 & 6563 & 7139 \\
$\mathbf{6 0}$ & 6900 & 7176 & 7866 & 8556 \\
$\mathbf{7 0}$ & 7210 & 7498 & 8219.4 & 8940 \\
$\mathbf{9 0}$ & 8009 & 8973 & 9203 & 10425 \\
\hline
\end{tabular}

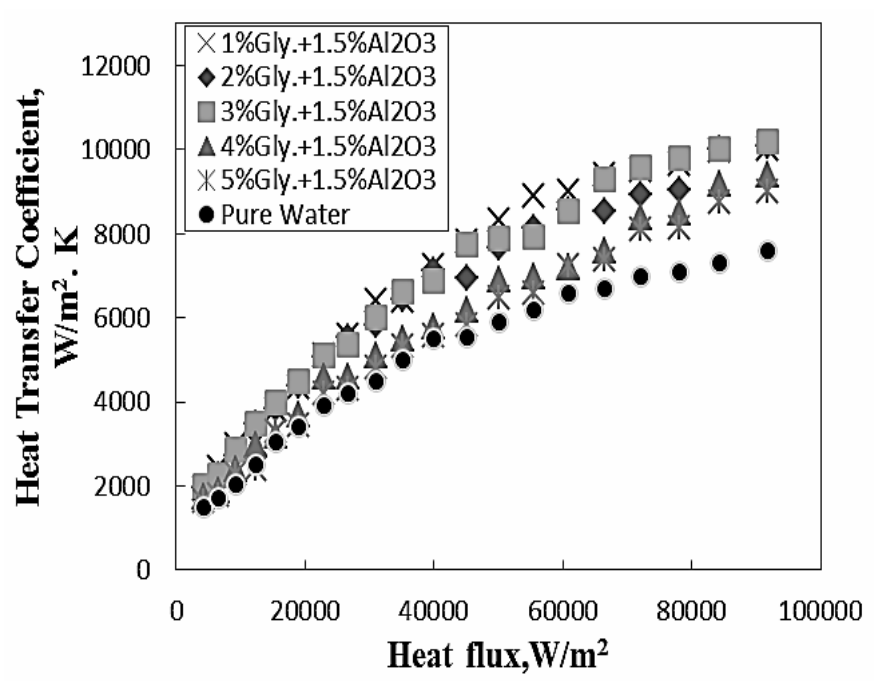

Fig. 8. Comparison between experimental heat transfer coefficient of base solution,Water/Glycerol and nano mixture of Water-glycerol $+\mathrm{Al}_{2} \mathrm{O}_{3}$ at $1.5 \%$ volumetric concentration of $\mathrm{Al}_{2} \mathrm{O}_{3}$

trations of glycerol in base solution have been experimentally investigated. Results demonstrated that:

- As expected, heat flux has a strong effect on the pool boiling heat transfer coefficient. It means that with increasing the heat flux, the pool boiling heat transfer coefficient dramatically increases. at presence of nanoparticles, higher heat transfer coefficients are reported compared to water/glycerol mixture without any nanoparticles.

- With increasing the concentration of nanoparticles, rate of increase of pool boiling heat transfer coefficient increases. It may refer to the effect of particle deposition on the heating surface that influences on the conductivity and roughness of surface. However, more experiments are needed to investi- gate the effect of nanoparticles on thermo-physical properties of surface and liquids.

- Results also revealed that presence of nanoparticles into mixture enhances the heat transfer coefficients about $25 \%$ at maximum dispersed nanoparticle concentration in comparison with base solutions.

\section{Nomenclatures}
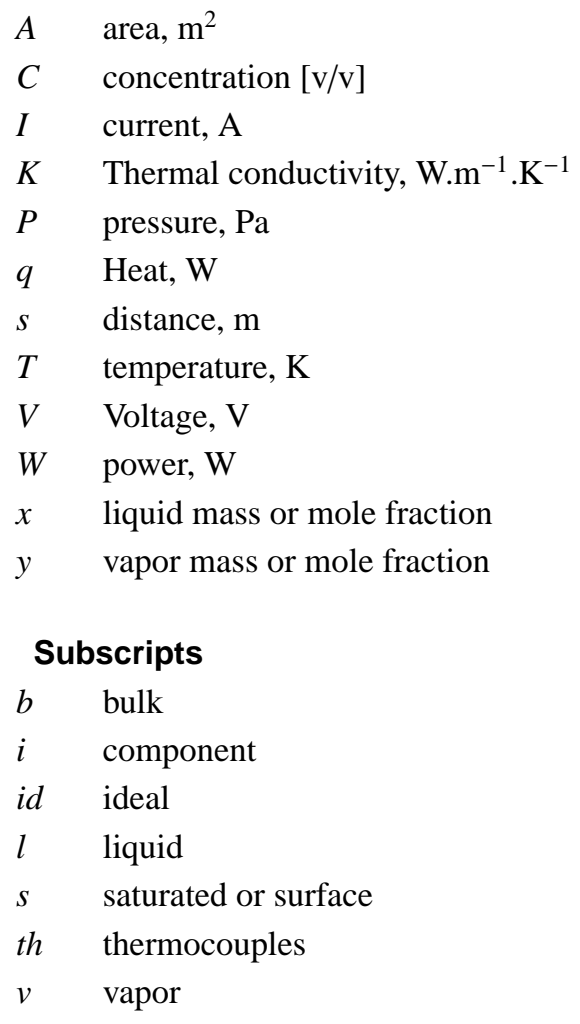

\section{Abbreviations}

A.A.E\% Absolute Average Enhancement 
Tab. 3. Enhancement values of heat transfer coefficient for 3\% volumetric Water-Glycerol for $0.5 \%$, $1 \%$ and $1.5 \%$ of $\mathrm{Al}_{2} \mathrm{O}_{3}$ nanoparticle

\begin{tabular}{lllll}
\hline $\mathbf{q} / \mathbf{A}$ & $\alpha$ (base fluid) & $\alpha$ Enhanced & $\alpha$ Enhanced & \\
{$\left[\mathbf{k W} / \mathbf{m}^{2}\right]$} & $\begin{array}{l}\text { Water-Glycerol } \\
{\left[\mathbf{W} / \mathbf{m}^{2} \cdot \mathbf{K}\right]}\end{array}$ & $\begin{array}{l}\mathbf{0 . 5} \% \mathbf{A l}_{2} \mathbf{O}_{3} \\
{\left[\mathbf{W} / \mathbf{m}^{2} \cdot \mathbf{K}\right]}\end{array}$ & $\begin{array}{l}\mathbf{1} \% \mathbf{A l}_{2} \mathbf{O}_{3} \\
{\left[\mathbf{W} / \mathbf{m}^{2} \cdot \mathbf{K}\right]}\end{array}$ & $\begin{array}{l}\mathbf{1 . 5} \% \mathbf{A l}_{2} \mathbf{O}_{3} \\
{\left[\mathbf{W} / \mathbf{m}^{2} \cdot \mathbf{K}\right]}\end{array}$ \\
\hline $\mathbf{1 0}$ & 2300 & 2415 & 2513 & 2875 \\
$\mathbf{2 0}$ & 3600 & 3780 & 4000 & 4500 \\
$\mathbf{4 0}$ & 5500 & 5775 & 6100 & 6875 \\
$\mathbf{6 0}$ & 6822 & 7163 & 7846 & 8528 \\
$\mathbf{7 0}$ & 7300 & 7665 & 8395 & 9600 \\
$\mathbf{9 0}$ & 7800 & 8715 & 9400 & 10210 \\
\hline
\end{tabular}

Tab. 4. Enhancement values of heat transfer coefficient for $4 \%$ volumetric Water-Glycerol for $0.5 \%$, $1 \%$ and $1.5 \%$ of $\mathrm{Al}_{2} \mathrm{O}_{3}$ nanoparticle

\begin{tabular}{|c|c|c|c|c|}
\hline $\begin{array}{l}q / A \\
{\left[k W / m^{2}\right]}\end{array}$ & $\begin{array}{l}\alpha \text { (base fluid) } \\
\text { Water-Glycerol } \\
{\left[\mathbf{W} / \mathbf{m}^{2} . \mathbf{K}\right]}\end{array}$ & $\begin{array}{l}\alpha \text { Enhanced } \\
0.5 \% \mathrm{Al}_{2} \mathbf{O}_{3} \\
{\left[\mathrm{~W} / \mathrm{m}^{2} . \mathbf{K}\right]}\end{array}$ & $\begin{array}{l}\alpha \text { Enhanced } \\
1 \% \mathrm{Al}_{2} \mathrm{O}_{3} \\
{\left[\mathrm{~W} / \mathbf{m}^{2} . \mathrm{K}\right]}\end{array}$ & $\begin{array}{l}\alpha \text { Enhanced } \\
1.5 \% \mathrm{Al}_{2} \mathrm{O}_{3} \\
{\left[\mathrm{~W} / \mathrm{m}^{2} . \mathrm{K}\right]}\end{array}$ \\
\hline 10 & 1800 & 1832 & 2088 & 2400 \\
\hline 20 & 2900 & 3101 & 3364 & 3704 \\
\hline 40 & 4600 & 4760 & 5336 & 5800 \\
\hline 60 & 5700 & 6042 & 6612 & 7200 \\
\hline 70 & 6590 & 6780 & 7645 & 8400 \\
\hline 90 & 7400 & 7709 & 8584 & 9400 \\
\hline
\end{tabular}

Tab. 5. Enhancement values of heat transfer coefficient for $5 \%$ volumetric Water-Glycerol for $0.5 \%$, $1 \%$ and $1.5 \%$ of $\mathrm{Al}_{2} \mathrm{O}_{3}$ nanoparticle

\begin{tabular}{lllll}
\hline $\mathbf{q} / \mathbf{A}$ & $\alpha$ (base fluid) & $\alpha$ Enhanced & $\alpha$ Enhanced & $\alpha$ Enhanced \\
{$\left[\mathbf{k W} / \mathbf{m}^{2}\right]$} & $\begin{array}{l}\text { Water-Glycerol } \\
{\left[\mathbf{W} / \mathbf{m}^{2} \cdot \mathbf{K}\right]}\end{array}$ & $\begin{array}{l}\mathbf{0 . 5 \%} \mathbf{A l}_{2} \mathbf{O}_{3} \\
{\left[\mathbf{W} / \mathbf{m}^{2} \cdot \mathbf{K}\right]}\end{array}$ & $\begin{array}{l}\mathbf{1} \% \mathbf{A l}_{2} \mathbf{O}_{3} \\
{\left[\mathbf{W} / \mathbf{m}^{2} \cdot \mathbf{K}\right]}\end{array}$ & $\begin{array}{l}\mathbf{1 . 5 \%} \mathbf{A l}_{2} \mathbf{O}_{3} \\
{\left[\mathbf{W} / \mathbf{m}^{2} \cdot \mathbf{K}\right]}\end{array}$ \\
\hline $\mathbf{1 0}$ & 1800 & 1908 & 2106 & 2286 \\
$\mathbf{2 0}$ & 2700 & 2862 & 3159 & 3429 \\
$\mathbf{4 0}$ & 4400 & 4664 & 5148 & 5588 \\
$\mathbf{6 0}$ & 5700 & 6042 & 6669 & 7239 \\
$\mathbf{7 0}$ & 6370 & 6552 & 7452 & 8089 \\
$\mathbf{9 0}$ & 7100 & 7526 & 8307 & 9017 \\
\hline
\end{tabular}

\section{Greek symbols}

$\alpha \quad$ Heat transfer coefficient, $\mathrm{W} \cdot \mathrm{m}^{-2} \cdot \mathrm{K}^{-1}$

$\beta \quad$ Constant

$\gamma \quad$ Constant

$\delta_{1}, \delta_{2}$ Tuning (fitting) Parameters, see modeling section.

\section{References}

1 Soltani S, Etemad S, Thibault J, Int. J. Heat Mass Tran., 45, (2009), 1555 1560.

2 Zhang J, Manglik RM, J. Non-Newton. Fluid Mech., 125, (2005), 123-134.

3 Choi SUS, ASME, 66, (1995), 99-105.

4 Das SK, Putra N, Roetzel W, Int. J. Multiphase. Flow, 29, (2003), 12371247.

5 Das SK, Putra N, Roetzel W, Int. J. Heat Mass Trans., 46, (2003), 851-862. 6 You SM, Kim JH, Kim KH, Appl. Phys. Lett., 83, (2003), 3374-3376.

7 Witharana S, Ph.D. thesis, Royal Institute of Technology; Stockholm, Sweden, 2003.

8 Vassllo P, Kumar R, Amico SD, Int. J. Heat Mass Trans., 47, (2004), 407411.

9 Tu JP, Dinh N, Theofanous T, $6^{\text {th }}$ International Symposium on Heat Transfer; Beijing, China, 2004.

10 Bang IC, Chang SH, Int. J. Heat Mass Trans., 48, (2005), 2407-2419.

11 Wen D, Ding Y, J. Nanoparticles Res., 7, (2005), 265-274.
12 Shi MH, Shuai MQ, Lai YE, Li YQ, Xuan M, $3^{\text {th }}$ International Heat Transfer Conference; Sydney, Australia, 2006.

13 Nguyen CT, Galanis N, Roy G, Divoux S, Gilbert D, $3^{\text {th }}$ International Heat Transfer Conference; Sydney, Australia, 2006.

14 Coursey JS, Kim J, J. Heat Fluid Flow, 29, (2008), 1577-1585.

15 Liu Z, Liao L, Int. J. Heat Mass Tran., 48, (2005), 2407-2419.

16 Trisaksri V, Wongwises S, Int. J. Heat Mass Tran., 52, (2009), 1582-1588.

17 Kathiravan R, Kumar A, Gupta R, Chandra R, Int. J. Heat Mass Tran., 53, (2010), 1673-1681.

18 Suriyawong A, Wongwises S, Exp Therm. Fluid Sci., 34, (2010), 992 999.

19 Ahmed O, Hamed MS, ICMF; Tampa, USA, 2010.

20 Kwark SM, Kumar R, Moreno G, Yoo J, You SM, Int. J. Heat Mass Tran., 53, (2010), 972-981.

21 Narayan GP, Anoop KB, Satesh G, Das SK, Int. J. Multiphase Flow, 34, (2008), 145-160.

22 Cieslinski JT, Kaczmarczyk TZ, Nano Scale Research Letters, 6, (2011), 220-229. 